\title{
Demografia de um povo indígena da Amazônia brasileira: os sateré-mawé
}

\author{
Pery Teixeira* \\ Marília Brasil $^{\star *}$ \\ Eliana Mesquita da Silva***
}

\begin{abstract}
Um levantamento sociodemográfico censitário participativo sobre a população sateré-mawé, realizado em 2002 e 2003, em duas terras indígenas e em quatro cidades situadas no oeste do Estado do Amazonas, revelou informações de relevância para a compreensão das características demográficas, econômicas, sociais e culturais daquele povo indígena. No cômputo geral, foram contados e entrevistados 7.502 indígenas nas terras indígenas e 998 nas áreas urbanas. 0 presente trabalho procura analisar a parcela dos dados levantados no que se refere às características sociodemográficas dos sateré-mawé, incluindo-se a estrutura etária e por sexo, a fecundidade, a mortalidade e a migração. O povo sateré-mawé apresenta uma repartição etária jovem, fruto de uma fecundidade elevada e de uma população idosa reduzida. Percebem-se intensos fluxos migratórios tanto no interior das terras indígenas onde habitam os sateré-mawé como em direção às cidades próximas, fluxos esses de caráter relativamente recente. Por sua vez, a mortalidade infantil no território indígena é elevada e espacialmente diferenciada, sendo maior nas cabeceiras de um dos dois principais rios que cortam o território sateré-mawé. Alguns elementos de determinação dos níveis e dos diferenciais da mortalidade das crianças são encontrados nas características socioeconômicas, de infraestrutura e nutricionais do povo sateré-mawé.
\end{abstract}

Palavras-chave: Povos indígenas. Distribuição etária. Fecundidade. Migração. Mortalidade infantil.

\section{Introdução}

No Brasil, os estudos demográficos da população indígena, neste início do século XXI, têm apresentado crescimento em termos de quantidade e qualidade sem precedentes na história da pesquisa científica sobre os povos indígenas. Embora ainda de forma tímida, a crescente diversidade das fontes de informação e sua melhora qualitativa têm contribuído sobremaneira para o enriquecimento das pesquisas e dos debates em torno da questão indígena.

Para o conjunto do país, a principal fonte de dados sociodemográficos espacialmente abrangentes sobre a população indígena é o censo demográfico, mais especificamente aqueles realizados em 1991 e 2000. Embora criticadas por especialistas, especialmente devido ao caráter de autodeclaração da

\footnotetext{
* Doutor em Demografia, professor adjunto da Faculdade de Estudos Sociais da Universidade Federal do Amazonas.

** Mestre em Demografia, professora assistente da Faculdade de Estudos Sociais da Universidade Federal do Amazonas.

*** Bacharel em Economia, professora da Universidade Estadual do Amazonas.
} 
origem (PAGLIARI et al., 2004), as informações geradas nessas fontes permitem traçar algumas das principais características demográficas e sociais das pessoas que se declararam indígenas nos dois censos demográficos.

Outras fontes de dados sobre a população indígena, a nível nacional, são constituídas pelo Sistema de Informações sobre Nascidos Vivos (Sinasc) e o Sistema de Informações sobre a Mortalidade (SIM), do Ministério da Saúde. Também no mesmo Ministério encontra-se o Sistema de Informação da Atenção à Saúde Indígena (Siasi). Embora ainda deficientes, ${ }^{1}$ esses sistemas oferecem perspectivas animadoras para o estudo da população indígena do Brasil. Por sua vez, o Ministério da Educação, por meio do Instituto Nacional de Estudos e Pesquisas Educacionais Anísio Teixeira (Inep), introduziu a variável cor/raça nos censos escolares do Brasil, a partir de 2005.

Algumas instituições, em associação com organizações indígenas, têm realizado levantamentos censitários esporádicos e localizados, de caráter participativo, em áreas amazônicas. Por iniciativa da Federação das Organizações Indígenas do Rio Negro (FOIRN) e de associações filiadas, foi realizado um censo indígena no Alto Rio Negro, Estado do Amazonas, em 1992 (AZEVEDO, 1994). Já em 2002/2003, uma parceria entre instituições governamentais, organizações indígenas e agências das Nações Unidas permitiu a realização de outro levantamento censitário, desta vez junto ao povo sateré-mawé, também no Estado do Amazonas (TEIXEIRA, 2005). Uma terceira investigação de campo foi realizada na cidade de São Gabriel da Cachoeira (AM), em 2004, pelo Instituto Socioambiental e pela FOIRN, em parceria com as associações de bairro da cidade (AZEVEDO, 2006).

$\mathrm{O}$ presente estudo aborda o segundo levantamento citado anteriormente, que foi idealizado e coordenado por seus autores. Intitulado Diagnóstico sócio-demográfico participativo da população sateré-mawé, a pesquisa cobriu a população sateré-mawé residente nas cidades de Maués, Parintins, Barreirinha e Nova Olinda do Norte e nas terras indígenas do Andirá-Marau e Koatá-Laranjal, no Estado do Amazonas, entre novembro de 2002 e outubro de 2003. No total, foram levantados 8.500 residentes autodeclarados sateré-mawé, correspondendo a um total de 1.759 domicílios, dos quais 228 nas áreas urbanas (com 998 moradores) e 1.531 nas terras indígenas (com 7.502 moradores).

\section{Informações sobre a área de estudo}

Nos cerca de 790 mil hectares da Terra Indígena Andirá-Marau, situada na bacia dos Rios Andirá e Marau, existem 91 comunidades (aldeias e sítios). Essas aldeias compõem as áreas ${ }^{2}$ indígenas dos Rios Andirá (49 comunidades), Marau (37 comunidades) e Uaicurapá (quatro comunidades). Na Terra Indígena Koatá-Laranjal, pertencente ao povo munduruku, existe outra aldeia sateré-mawé

Das quatro cidades onde foi realizado o levantamento sociodemográfico, três (Barreirinha, Maués e Parintins) são sedes dos municípios onde se situam os Rios Andirá, Marau e Uaicurapá. A outra cidade, Nova Olinda do Norte, sede do município de mesmo nome, fica próxima de Vila Batista II, aldeia situada na Terra Indígena Koatá-Laranjal, município de Borba. ${ }^{3}$

A ampla maioria (88\%) da população sateré-mawé recenseada reside nas duas terras indígenas citadas (Andirá-Marau e Koatá-Laranjal). A população é mais numerosa nas bacias dos Rios Andirá e Marau. Os Rios Uaicurapá e Mari-Mari (no Koatá-Laranjal) concentram número reduzido de aldeias e de habitantes e são destinos de

\footnotetext{
1 Uma avaliação crítica do Siasi foi feita recentemente por Sousa, Scatena e Santos (2007).

2 No decorrer deste trabalho, a referência aos termos área indígena, território indígena ou terra indígena (em minúsculas) tem caráter genérico, indicando o espaço geográfico situado no interior das Terras Indígenas Andirá-Marau e Koatá-Laranjal. ${ }^{3}$ A sede do município de Borba não foi incluída na pesquisa por estar a uma grande distância da referida comunidade e, segundo informações obtidas no período do levantamento, a presença indígena era praticamente nula.
} 
TABELA 1

População sateré-mawé, segundo local de residência 2002/2003

\begin{tabular}{lrr}
\hline \multirow{2}{*}{ Local de residência } & \multicolumn{2}{c}{ População } \\
\cline { 2 - 3 } & Total & $\%$ \\
\hline Área urbana & 998 & $\mathbf{1 1 , 7}$ \\
Parintins & 512 & 6,0 \\
Barreirinha & 276 & 3,2 \\
Maués & 200 & 2,4 \\
Nova Olinda do Norte & 10 & 0,1 \\
Área indígena & 7.502 & $\mathbf{8 8 , 3}$ \\
Andirá & 3.795 & 44,6 \\
Marau & 3.288 & 38,7 \\
Uaicurapá & 292 & 3,4 \\
Koatá-Laranjal & 127 & 1,5 \\
Total & $\mathbf{8 . 5 0 0}$ & $\mathbf{1 0 0 , 0}$ \\
\hline
\end{tabular}

Fonte: Base de dados do Diagnóstico Sócio-Demográfico Participativo da População Sateré-Mawé.

fluxos migratórios relativamente recentes originários das aldeias do Andirá (décadas de 1980, no Koatá-Laranjal, e de 1990, no Uaicurapá).

Apesar de o maior número de sateré-mawé residir em aldeias, não podem ser desconsiderados os que moram nas cidades próximas, cuja quantidade sugere a existência de um processo migratório significativo com destino à área urbana. Entre as quatro cidades, merecem destaque os residentes em Parintins, que constituem mais da metade do total da etnia naquelas áreas urbanas.

\section{Composição por sexo e idade}

\section{Distribuição etária da população}

A estrutura etária dos sateré-mawé é variável conforme o quadro domiciliar considerado, exceto para idades a partir de 65 anos, as quais têm o mesmo peso relativo tanto em território indígena como nas cidades próximas.

Os residentes em áreas indígenas apresentam estrutura etária típica de povos em processo de recuperação populacional, caracterizando-se por níveis de natalidade elevados e de mortalidade em declínio. Como reflexo da alta natalidade em áreas indígenas sateré-mawé, mais da metade dessa população tem idade inferior a 15 anos (Tabela 2). Tal proporção não é estranha à Região Amazônica, para a qual diversos estudos indicam a "juventude" de uma quantidade expressiva de povos indígenas, que retomaram altos níveis de fecundidade, encontrando-se também em processo de recuperação populacional (FLOWERS, 1994; SOUZA; SANTOS, 2001; PAGLIARO, 2002; PAGLIARO et al., 2001; 2003).

Nas cidades pesquisadas, a composição etária dos sateré-mawé estaria refletindo o efeito de níveis de fecundidade e de natalidade menores do que os observados nas terras indígenas, muito embora os altos valores da natalidade ainda persistentes nas cidades (32,1 óbitos por mil nascidos vivos) sejam bem mais elevados do que os do Brasil urbano (21,1 por mil nascidos vivos). Existe também um expressivo componente migratório na distribuição etária da população das cidades estudadas, o qual ocorre em todas as idades, especialmente nos segmentos de adultos e idosos. Com efeito, entre os moradores com 30 anos e mais de idade, $95 \%$ são migrantes.

Devido à elevada fecundidade existente entre os sateré-mawé, crianças e adolescentes são maioria absoluta nas terras indígenas (52,6\% do total) e correspondem a $45 \%$ da população indígena das cidades. É interessante notar que o forte peso do 
número de crianças e adolescentes em território indígena reflete o que se observa no rural especifico ${ }^{4}$ do Brasil e, em particular, na população indígena residente na zona rural do Estado do Amazonas.

Os sateré-mawé com 65 anos ou mais de idade respondem por $4,2 \%$ da população total, tanto nas cidades quanto nas terras indígenas. Esta proporção é equivalente à do total de indígenas nesta faixa etária residentes em áreas rurais ou no rural específico do Brasil, mas é inferior àquela referente à população urbana indígena do país, em que os idosos representam cerca de $7 \%$.

Observando-se a pirâmide etária dos sateré-mawé residentes em áreas indígenas (Gráfico 1), percebe-se que, a partir dos 40 anos, a pirâmide se afunila para apresentar, em seguida, um "excesso" de população (aproximadamente dos 55 aos 65 anos para as mulheres e dos 60 a 69 anos para os homens). Uma primeira hipótese de explicação para o fenômeno poderia referir-se a problemas na declaração de idade, por desconhecimento do ano do próprio nascimento. Embora seja corrente entre as populações idosas em zona rural, a hipótese parece improvável neste caso dos sateré-mawé, já que a irregularidade localiza-se em grupos etários específicos e já se manifestara três anos antes, no Censo Demográfico de 2000.5 Ademais, tal comportamento não é generalizado no Estado do Amazonas, apesar de ser observado em outras terras indígenas amazonenses.

Outra hipótese de explicação para as irregularidades nas faixas etárias superiores poderia estar relacionada com algum evento demográfico dos últimos 60 anos que tivesse levado a essa "desestruturação" da composição etária dos sateré-mawé. Faltam, todavia, informações e registros que possam ser utilizados para confirmar uma situação como essa.

Resta levar em consideração o pressuposto de que os entrevistados tenham deliberadamente declarado a idade errada. Caso tenha ocorrido, esse fato poderia estar

TABELA 2

Distribuição da população sateré-mawé, por grupos etários, segundo local de residência 2002/2003

\begin{tabular}{lcccc}
\hline Local de residência & $\mathbf{0}$ a $\mathbf{1 4}$ anos & $\mathbf{1 5}$ a $\mathbf{6 4}$ anos & $\mathbf{6 5}$ anos e mais & Total \\
\hline Área indígena & 52,6 & 43,2 & 4,2 & 100,0 \\
Marau & 53,1 & 43,2 & 3,7 & 100,0 \\
Andirá & 51,8 & 43,4 & 4,8 & 100,0 \\
Uaicurapá & 55,8 & 41,1 & 3,1 & 100,0 \\
Koatá-Laranjal & 56,7 & 39,4 & 3,9 & 100,0 \\
Área urbana & 45,0 & 50,6 & 4,1 & 100,0 \\
Parintins & 46,5 & 49,8 & 3,7 & 100,0 \\
Barreirinha & 44,9 & 51,4 & 3,3 & 100,0 \\
Maués & 41,0 & 52,0 & 6,0 & 100,0 \\
Nova Olinda do Norte (1) & 50,0 & 40,0 & 10,0 & 100,0 \\
Total & $\mathbf{5 1 , 7}$ & $\mathbf{4 4 , 0}$ & $\mathbf{4 , 2}$ & $\mathbf{1 0 0 , 0}$ \\
\hline
\end{tabular}

Fonte: Base de dados do Diagnóstico Sócio-Demográfico Participativo da População Sateré-Mawé. IBGE, base de microdados do Censo Demográfico de 2000.

(1) Dados referentes a um total de dez moradores.

\footnotetext{
${ }^{4}$ Em publicação recente, o IBGE considerou como "rural específico" as áreas rurais dos municípios que possuem terras indígenas, incluindo-se estas últimas (IBGE, 2005).

${ }^{5}$ Essa afirmação baseia-se na distribuição etária estimada a partir da amostra censitária de 2000 dos indígenas residentes nas áreas rurais dos municípios de Barreirinha e Maués. A Terra Indígena Andirá-Marau, onde vivem mais de $90 \%$ dos sateré-mawé cobertos pelo Diagnóstico Sócio-Demográfico de 2002/2003, está situada no interior dessas áreas rurais, onde é desprezível a quantidade de indígenas pertencentes a outras etnias.
} 
GRÁFICO 1

Distribuição da população sateré-mawé em terras indígenas, por sexo e idade 2002/2003

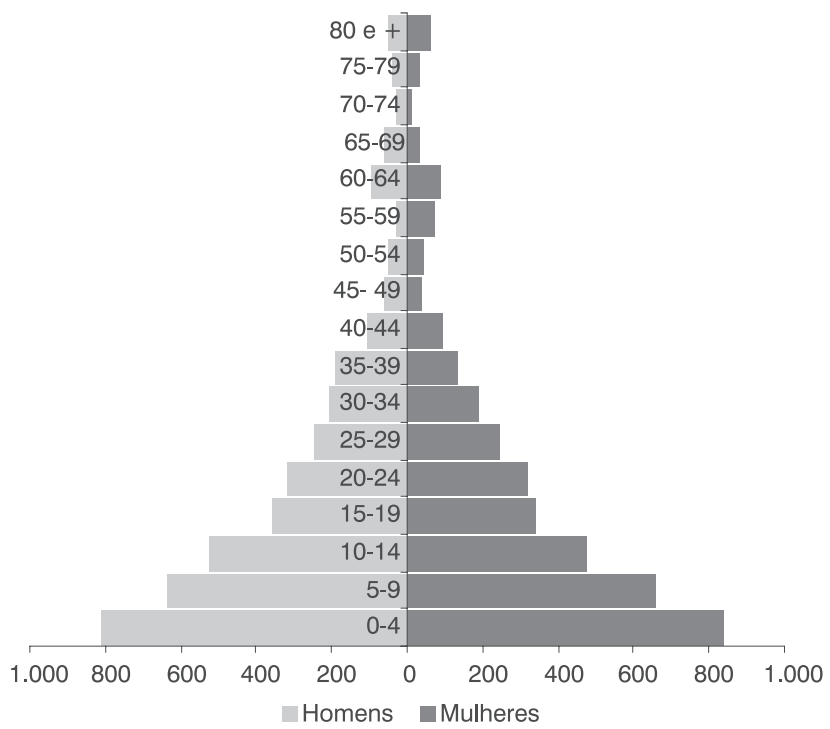

Fonte: Base de dados do Diagnóstico Sócio-Demográfico Participativo da População Sateré-Mawé.

relacionado à necessidade que teriam as pessoas de se mostrar legalmente aptas a adquirir o status de aposentadas antes de completar a idade referida em lei. ${ }^{6}$ Tal situação parece estar se verificando, em escala menor, em algumas áreas específicas do Estado do Amazonas e da Região Norte. Com uma proporção de aposentados próxima à dos sateré-mawé, os povos indígenas do Alto Solimões (AM) também apresentam essa "irregularidade" da distribuição etária nas idades avançadas, embora menos acentuada.

Nas áreas urbanas, percebe-se uma relativa redução dos efetivos do primeiro grupo etário (Gráfico 2). Entre as hipóteses de explicação para o fato, podem ser citadas a natalidade decrescente e a não-declaração das crianças pelos pais (no caso dos menores de dez anos, principalmente). A ocorrência de subdeclaração de crianças parece constituir, aliás, um fenômeno corrente nas populações indígenas brasileiras residentes em áreas urbanas (IBGE, 2005, p.45). 7 No caso dos sateré-mawé, essa característica afeta preferencialmente os meninos, já que eles são minoria (139, contra 168 meninas) nos dois primeiros grupos etários nas cidades em estudo. Dada a falta de uma explicação plausível para a situação, não se pode descartar a ocorrência de flutuações aleatórias nos dados.

\footnotetext{
${ }^{6}$ Segundo a legislação brasileira, os trabalhadores rurais sem carteira assinada, os que participam da agricultura familiar ou da agricultura de subsistência, podem se aposentar aos 55 anos, no caso das mulheres, e aos 60 , no dos homens. Os indígenas enquadram-se nessa categoria de trabalhadores (para mais detalhes, ver KRETER; BACHA, 2003).

$7 \mathrm{Na}$ cidade de Parintins, onde foram contados 512 sateré-mawé pelo Diagnóstico Sócio-Demográfico de 2002/2003, o Censo Demográfico de 2000 levantou apenas 61 habitantes indígenas (seis, na amostra) - de todas as etnias. Dada a inexistência de uma migração de sateré-mawé em massa para a cidade em tão pouco tempo, constata-se uma subenumeração dos indígenas em 2000 , que poderia ser atribuída ao não reconhecimento da identidade étnica pela maioria dos indígenas recenseados. Assim, não causaria surpresa se alguns dos que não se autodeclararam indígenas no censo demográfico de 2000, quando localizados pelos entrevistadores sateré-mawé em 2002/2003, não se dispusessem a declarar os filhos como indígenas. De fato, durante o levantamento deste último ano, pelo menos duas mulheres saterémawé negaram-se a admitir a identidade indígena dos filhos mais novos.
} 
GRÁFICO 2

Distribuição da população sateré-mawé em área urbana, por sexo e idade 2002/2003

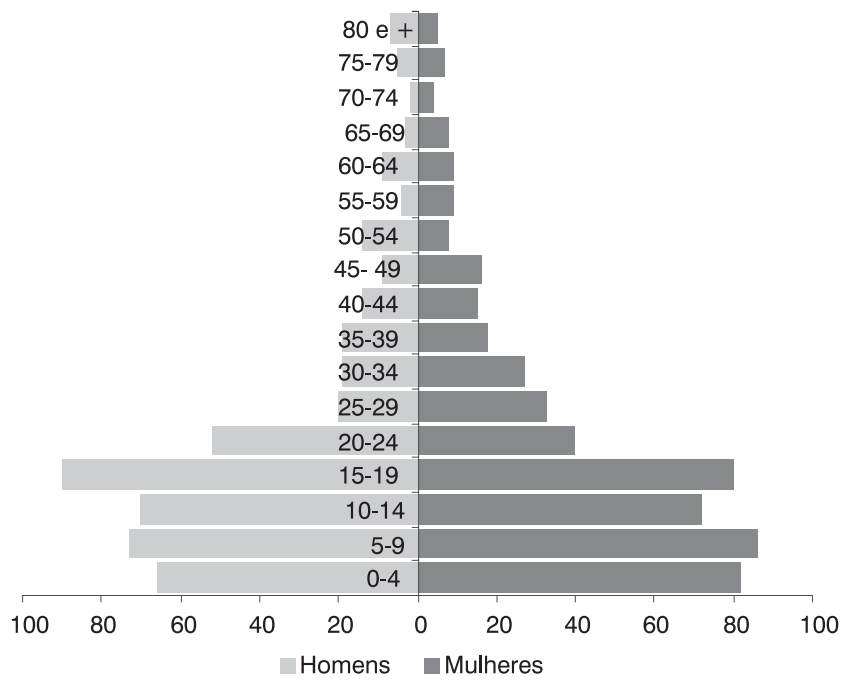

Fonte: Base de dados do Diagnóstico Sócio-Demográfico Participativo da População Sateré-Mawé.

TABELA 3

Distribuição da população sateré-mawé, por sexo, segundo local de residência 2002/2003

\begin{tabular}{lccc}
\hline Local de residência & Homens & Mulheres & Razão de sexo \\
\hline Área indígena & $\mathbf{3 . 7 4 7}$ & $\mathbf{3 . 6 2 8}$ & $\mathbf{1 0 3 , 3}$ \\
Marau & 1.635 & 1.597 & 102,4 \\
Andirá & 1.889 & 1.835 & 102,9 \\
Uaicurapá & 155 & 137 & 113,1 \\
Koatá-Laranjal & 68 & 59 & 115,3 \\
Área urbana & $\mathbf{4 7 8}$ & $\mathbf{5 2 5}$ & $\mathbf{9 1 , 0}$ \\
Total & $\mathbf{4 . 2 2 5}$ & $\mathbf{4 . 1 5 3}$ & $\mathbf{1 0 1 , 7}$ \\
\hline
\end{tabular}

Fonte: Base de dados do Diagnóstico Sócio-Demográfico Participativo da População Sateré-Mawé.

\section{Repartição por sexo}

No total (terras indígenas mais área urbana), a população masculina sateré-mawé é superior à feminina (Tabela 3). No entanto, considerando-se a situação de domicílio, verifica-se que há mais mulheres do que homens nas cidades e mais homens do que mulheres nas terras indígenas, o que reproduziria padrão de distribuição urbano-rural do país. A razão de sexo em área indígena é de 103,3 homens para cada 100 mulheres, bastante superior ao que se verifica nas cidades (91 homens para 100 mulheres).
Tais valores poderiam estar indicando uma migração feminina para as cidades superior à masculina.

Na área indígena não parece haver diferença numérica significativa entre homens e mulheres até aproximadamente 30 anos de idade. A partir daí, a participação masculina passa a ser superior até os 80 anos de idade, com exceção do grupo etário 55-59 anos e início do grupo 60-64 anos, em que as mulheres são amplamente superiores. Assim, aparentemente, a longevidade das mulheres sateré-mawé vai aparecer apenas em idades muito avançadas. 
Já nas cidades, a superioridade numérica das mulheres a partir de 25 anos de idade, que se pode notar no Gráfico 2, está relacionada à maior migração diferencial das mulheres, nessas idades, com destino às cidades, o que explicaria a menor população feminina, nas idades correspondentes, em território indígena. $\mathrm{Na}$ área indígena, os homens são maioria nas idades idosas (70 anos e mais), o que não deveria ocorrer devido à sobremortalidade masculina, a não ser que as mulheres tenham migrado mais do que os homens também em tempos pretéritos. Nas áreas urbanas, a quantidade de mulheres nas idades mencionadas é superior à dos homens e quase todas são migrantes, mas, nesse caso, a explicação poderia estar mais na mortalidade diferencial do que na maior migração feminina.

\section{Fecundidade e reprodução}

Para o total dos sateré-mawé, a taxa bruta de natalidade foi estimada em 48,6 nascidos vivos por mil habitantes (Tabela 4). Os residentes no território indígena apresentavam maior nível de natalidade do que os das cidades. Apesar de haver efeito dos pequenos números na estimativa das zonas urbanas (apenas 28 nascimentos informados), o que aumenta a imprecisão do resultado, deve ser levada em conta a expressiva diferença, de 18,6 nascimentos por mil habitantes, entre a natalidade na área indígena e na cidade.
Quando consideradas as localidades que compõem as áreas indígenas, constata-se que também ali existem diferenças nos níveis de natalidade, embora menos significativas do que aquelas observadas entre o território indígena e as cidades vizinhas. Marau apresentou 53,5 nascimentos por mil habitantes, enquanto Andirá contou com 46,9. Esses indicadores sugerem que talvez haja comportamentos reprodutivos diversos, apesar de essas áreas apresentarem grandes semelhanças quanto às características sociais, econômicas e culturais.

Em consonância com a alta natalidade, são especialmente elevados os níveis de fecundidade dos sateré-mawé, que atingem taxas em torno de oito filhos por mulher. Esses resultados são tão expressivos que superam até a elevada média de 6,2 filhos das mulheres indígenas residentes nas áreas rurais dos municípios brasileiros onde existem terras indígenas. Porém, aproximam-se de comportamentos reprodutivos adotados por outras sociedades indígenas do país, como os kaiabi (PAGLIARO, 2002), xavante (SOUZA; SANTOS, 2001), waurrá-xingu (PAGLIARO et al., 2001), entre outros.

Da mesma forma como ocorre para a natalidade, constata-se que os níveis de fecundidade variam bastante entre terras indígenas e áreas urbanas e que entre o Andirá e o Marau a variação é pequena. Assim, se as áreas urbanas e as terras indígenas apresentam formas distintas de realizar o potencial reprodutivo das mulheres sateré-

TABELA 4

Nascidos vivos, Taxa Bruta de Natalidade, Taxa de Fecundidade Total e idade média à fecundidade na população sateré-mawé, segundo local de residência 2002/2003

\begin{tabular}{lcccc}
\hline Local de residência & $\begin{array}{c}\text { Nascidos } \\
\text { vivos }\end{array}$ & $\begin{array}{c}\text { Taxa Bruta de } \\
\text { Natalidade (nascidos } \\
\text { vivos por mil hab.) }\end{array}$ & $\begin{array}{c}\text { Taxa de } \\
\text { Fecundidade Total } \\
\text { (filhos por mulher) }\end{array}$ & $\begin{array}{c}\text { Idade média à } \\
\text { fecundidade }\end{array}$ \\
\hline Área indígena & $(1)$ 380 & 50,7 & 8,1 & 29,1 \\
Marau & 176 & 53,5 & 8,5 & 28,8 \\
Andirá & 178 & 46,9 & 7,9 & 29,9 \\
Área urbana & 32 & 32,1 & 5,1 & 31,4 \\
Total & $\mathbf{4 1 2}$ & $\mathbf{4 8 , 6}$ & $\mathbf{7 , 9}$ & $\mathbf{2 9 , 5}$ \\
\hline
\end{tabular}

Fonte: Base de dados do Diagnóstico Sócio-Demogrãfico Participativo da População Sateré-Mawé.

(1) Incluem os nascimentos das áreas do Uaicurapá e do Koatá-Laranjal, cuja reduzida quantidade não permite o cálculo de taxas confiáveis. 
-mawé, parece que entre as duas maiores subáreas também existem essas diferenças.

A diferença de fecundidade entre as terras indígenas e a área urbana é de três filhos por mulher. Apesar disso, a fecundidade das mulheres sateré-mawé residentes na zona urbana apresenta-se ainda em patamares elevados (5,1 filhos por mulher), sendo acompanhada por aquela das moradoras urbanas não-indígenas (4,3 filhos por muIher), o que não chega a surpreender, dada a mesma origem rural (e a mesma recente imigração) da maioria das moradoras das cidades em foco.

Por outro lado, se confrontados com o nível de fecundidade das áreas indígenas, esses dois valores urbanos da fecundidade estariam a indicar uma forte influência da cultura urbana sobre o comportamento reprodutivo das mulheres indígenas habitantes da cidade, não obstante o tempo médio relativamente reduzido em que aí residem (como se verá no item referente às migrações).

Nas áreas indígenas, a idade média à fecundidade das mulheres sateré-mawé é de 29,1 anos. ${ }^{8}$ Elas começam a ter filhos cedo e continuam a tê-los por muito tempo, muitas delas até idades próximas de 50 anos. A área do Rio Andirá, cuja fecundidade é inferior àquela verificada na região do Rio Marau, apresenta maior idade média à fecundidade.

É significativa a gravidez em idades precoces nas terras indígenas, onde foram encontradas mães com idade inferior a 15 anos. Tal situação é relativamente comum em outras sociedades indígenas, como, por exemplo, os kaiabi e os xavante (SOUZA; SANTOS, 2001; PAGLIARO, 2002).

Já na área urbana, a idade média à fecundidade das mulheres sateré-mawé $(31,4$ anos) é superior à das terras indígenas. $\mathrm{O}$ fenômeno repete-se quando se comparam as áreas urbanas e indígenas do Brasil, e está relacionado aos diferenciais de fecundidade entre esses dois contextos geográficos.

\section{Migração $^{9}$}

No Levantamento sócio-demográfico participativo, considerou-se migrante a pessoa com dez anos ou mais de idade que tenha feito algum deslocamento espacial (aldeia $x$ aldeia, aldeia $x$ cidade ou vice-versa) e fixado moradia no local onde se encontrava residindo no momento da coleta de campo, qualquer que tenha sido o período em que este deslocamento se realizou. Desta forma, é possível identificar as mudanças ocorridas dentro das áreas indígenas ou entre as áreas indígenas e as cidades. ${ }^{10}$

Os sateré-mawé apresentam expressiva mobilidade espacial, tanto no interior das terras indígenas como em direção às cidades situadas nas proximidades, às áreas rurais próximas ou a cidades mais distantes (neste último caso está Manaus, capital do Amazonas). Com efeito, $56,5 \%$ de todos os moradores entrevistados já fizeram algum movimento migratório. Nas áreas urbanas, a proporção de migrantes entre os sateré-mawé eleva-se para $87 \%$, aqui incluídos os que nasceram na cidade e passaram algum tempo morando em outro local $(2,9 \%)$. Nas terras indígenas também se verificam movimentos migratórios importantes entre as comunidades, os quais envolvem a metade da população (50,2\%). Esses movimentos parecem mais intensos no Marau $(56,5 \%$ de migrantes) do que no Andirá (42,4\%).

\section{Fluxos migratórios no interior das terras indígenas}

As mudanças de residência nas áreas indígenas constituem fenômeno frequente e ocorrem de uma aldeia para outra dentro

\footnotetext{
${ }^{8}$ Essa idade média é mais elevada do que os 26,7 anos do conjunto das indígenas brasileiras, porém está próxima dos 28,4 anos das residentes no rural específico (IBGE, 2005, p. 80).

${ }^{9}$ As informações sobre migração, no Diagnóstico sócio-demográfico participativo da população sateré-mawé, foram obtidas por meio de perguntas a todas as pessoas com dez anos ou mais de idade.

10 No caso das famílias residentes na Terra Indígena Koatá-Laranjal, do povo munduruku, no município de Borba, os entrevistados urbanos eram residentes na cidade de Nova Olinda do Norte, já que na cidade-sede de Borba não havia registro de moradores sateré-mawé.
} 
da mesma área (Marau, por exemplo), entre áreas diferentes da mesma terra indígena (do Andirá para o Marau, do Marau para - Uaicurapá ou outro fluxo) ou, ainda, entre terras indígenas (Andirá-Marau para Koatá-Laranjal ou vice-versa). Todavia, suas características podem variar segundo a área indígena considerada ou de acordo com o tempo histórico em que esses movimentos se dão, tendo, como determinações, fatores sociais, culturais e econômicos diversos.

De acordo com os dados levantados e depoimentos colhidos nas comunidades sateré-mawé, as migrações no interior da Terra Indígena Andirá-Marau ocorrem há muito tempo e continuavam a ocorrer quando foi realizado o Diagnóstico sócio-demográfico. Cerca de $60 \%$ do total de migrantes fizeram sua migração dez anos ou mais antes do levantamento realizado. Os outros 39\% realizaram seu último movimento migratório há menos de dez anos, indicando que a migração é intensa nos tempos atuais.

O Gráfico 3 mostra o contingente de migrantes que fizeram seu último movimento dentro das áreas indígenas, segundo o tempo de migração. Sua observação sugere que os fluxos migratórios recentes são compostos por população jovem e adulta-jovem e confirma o caráter antigo da migração dentro das terras indígenas, já que existem contingentes importantes de migrantes em todas as faixas etárias, inclusive de idosos. Ressalte-se ainda que a quantidade significativa de migrantes com idade inferior a 25 anos naqueles fluxos migratórios ocorridos há dez anos ou mais (portanto, com menos de 15 anos de idade quando migraram) pode estar indicando um componente familiar importante nesses deslocamentos (Gráfico 3).

Se não for levado em conta o tempo de residência, os homens são maioria entre os migrantes da área indígena, embora em pequena escala. Porém, quando se considera a idade dos migrantes, fica mais clara a dimensão de gênero nos deslocamentos dos sateré-mawé. Com efeito, nas migrações mais antigas, as mulheres eram minoritárias em praticamente todas as faixas etárias. Já nos dez anos que antecederam a pesquisa, a quantidade de homens e mulheres praticamente se equiparou, sendo as mulheres numericamente superiores até aproximadamente os 30 anos de idade, para, depois, tornarem-se minoria.

Razões diversificadas levam o sateré-mawé a migrar de uma comunidade para outra, situada ou não numa mesma área indígena. Excetuando-se o acompanhamento de familiares (48,3\% dos casos), os motivos mais comuns associados a esses fluxos

GRÁFICO 3

Distribuição dos migrantes sateré-mawé na área indígena, por idade e sexo, segundo tempo de migração 2002/2003
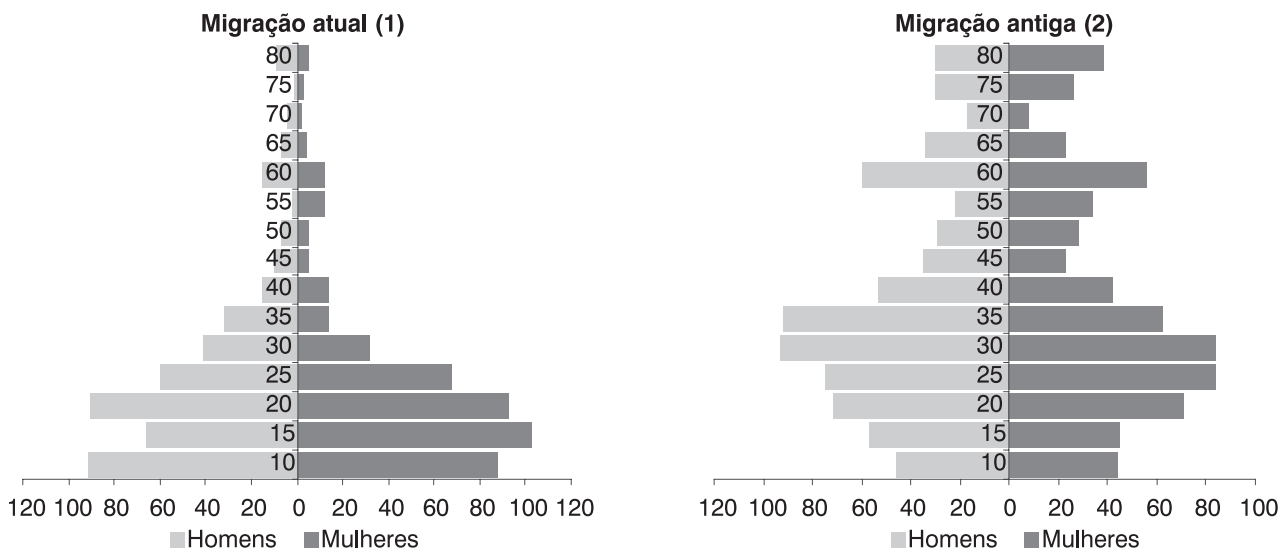

Fonte: Base de dados do Diagnóstico Sócio-Demográfico Participativo da População Sateré-Mawé

(1) Menos de 10 anos de moradia na residência atual.

(2) Dez anos ou mais de moradia na residência atual. 
migratórios "internos" são a constituição de família $(28,9 \%)$, os conflitos na comunidade $(6,0 \%)$, a transferência/procura de trabalho (4,8\% dos casos) e a educação dos filhos $(3,2 \%)$ (Tabela 5).

Os que declararam ter mudado de aldeia para constituir família são aqueles que passaram a viver na comunidade de residência do cônjuge após o casamento. Esse contingente é constituído, em sua maioria, por mulheres. ${ }^{11} \mathrm{Na}$ área do Marau convém observar que, se as mulheres com menos de 50 anos de idade, que migraram em período mais recente e por motivo de casamento, correspondem a quase o dobro dos homens nas mesmas condições, essa vantagem é reduzida quanto se trata de mulheres mais velhas e com migração mais antiga.

Os deslocamentos por motivo de trabaIho tornaram-se mais frequentes nos últimos anos, devido ao assalariamento crescente nas áreas indígenas, relacionado principalmente à criação e expansão de serviços de educação e saúde nas comunidades. Os professores indígenas são os que mais se deslocam por motivo profissional, especialmente ao assumir o cargo ou ao substituir um colega em outra comunidade. De fato, 90 dos 142 professores $(63,4 \%)$ não nasceram nas aldeias em que residiam na época da entrevista, sendo a maioria deles constituída de migrantes recentes, com menos de dez anos naquelas comunidades. Metade destes últimos declarou a transferência de trabalho como causa da migração. Para aqueles de migração mais antiga, menos de $10 \%$ declararam razões de trabalho para a sua mudança de comunidade.

A mudança de comunidade por motivo de trabalho não ocorre para os agentes indígenas de saúde (AIS), que formam, juntamente com os professores indígenas, os dois mais importantes grupos profissionais nas áreas indígenas estudadas. A maioria dos 69 agentes de saúde em atividade é constituída por migrantes antigos, que se deslocaram por motivos pouco relacionados com a transferência ou a procura de emprego. Na realidade, o trabalho dos AIS, contrariamente ao dos professores indígenas,

TABELA 5

Distribuição dos migrantes sateré-mawé na área indígena, por tempo de residência na comunidade, segundo motivo da migração 2002/2003

Em porcentagem

\begin{tabular}{lrrr}
\hline \multirow{2}{*}{ Motivo da migração } & \multicolumn{2}{c}{ Tempo de residência } \\
\cline { 2 - 4 } & Menos de dez anos & Dez anos ou mais & Total \\
\hline Constituição de família & 27,0 & 30,0 & 28,9 \\
Conflito interno da comunidade & 6,6 & 6,7 & 2,0 \\
Transferência de trabalho & 4,6 & 0,9 & 1,2 \\
Escassez de alimentos (caça, pesca, roça, etc.) & 1,3 & 1,1 & 2,4 \\
Procura de trabalho & 3,2 & 1,8 & 3,2 \\
Procura de melhores condições de educação & 4,8 & 2,2 & 2,1 \\
Procura de melhores condições de saúde & 1,5 & 2,4 & 48,3 \\
Acompanhando os pais, o(a) esposo(a) ou outros familiares & 45,6 & 50,0 & 4,8 \\
Outro motivo & 4,3 & 5,1 & 0,8 \\
Não sabe & 1,0 & 0,7 & $\mathbf{1 0 0 , 0}$ \\
Total & $\mathbf{1 0 0 , 0}$ & $\mathbf{1 0 0 , 0}$ & $\mathbf{2 . 3 2 1}$ \\
N. absolutos & $\mathbf{9 1 0}$ & $\mathbf{1 . 4 1 1}$ & \\
\hline
\end{tabular}

Fonte: Base de dados do Diagnóstico Sócio-Demogrãfico Participativo da População Sateré-Mawé.

\footnotetext{
${ }^{11}$ Em uma recente pesquisa sobre os povos indígenas do Alto Rio Negro, Azevedo (2004, p.4) verificou que as mulheres, depois de casadas, devem residir na comunidade do marido.
} 
costuma ser desenvolvido junto à própria comunidade onde ele já residia. ${ }^{12}$

Merece destaque a mudança de aldeia por motivo de conflitos na comunidade. Entre os sateré-mawé, algumas comunidades foram criadas a partir da ocorrência desses desentendimentos nas aldeias de origem. Um desses conflitos, ocorrido na Terra Indígena Andirá-Marau, merece ser lembrado por suas consequências. Os fatos deram-se na comunidade de Araticum Novo, no Andirá, no fim dos anos 1970, e fizeram com que várias famílias (cerca de 40 pessoas) acabassem por se fixar em terras do povo munduruku, no Koatá-Laranjal, ali fundando uma aldeia sateré-mawé (BATISTA, 2001). Posteriormente (por volta de 1990), por desentendimentos internos, uma parte dos migrantes e suas famílias regressaram ao Andirá-Marau, fundando outra comunidade (Vila Batista I) às margens do Uaicurapá, a alguns quilômetros de distância de sua aldeia original, o Araticum Novo.

Embora com pequena redução, deslocamentos a partir das áreas antigas continuam no presente: dos migrantes recentes, $26,5 \%$ saíram das áreas antigas para as novas, proporção essa ainda bastante superior ao peso numérico das áreas antigas no total da população $(18,2 \%)$.

As informações levantadas sugerem que, anteriormente, muitas famílias deslocavam-se para áreas mais favorecidas em busca de oportunidades de educação para as crianças ou de serviços de saúde pública, geralmente concentrados em alguns locais da área indígena. Tais deslocamentos, de modo geral, eram feitos da cabeceira dos rios - áreas do povoamento original - para locais mais próximos à foz, isto é, próximos às cidades vizinhas. Uma das causas desse tipo de deslocamento seria, provavelmente, a oportunidade de residir em aldeias mais favorecidas por alguns dos serviços públicos essenciais e por local de comercialização dos produtos agrícolas e de coleta e de compra de suprimentos para a família. $\mathrm{Na}$ opinião de Lorenz (1992), a proliferação de aldeias situadas nas margens dos Rios Marau e Andirá, desde as primeiras décadas do século $X X$, deve-se à interferência de diferentes instituições na vida tradicional dos sateré-mawé, como as missões religiosas, o extinto SPI (atual Funai), os regatões, além das epidemias.

Os moradores que indicaram a procura de melhores condições de educação como motivo para migrar de uma aldeia para outra se diferenciam segundo a época em que mudaram de residência. A migração com este tipo de motivação tornou-se mais intensa nos dez anos anteriores à pesquisa. Não se dispõe de informações sobre a cobertura e a qualidade do ensino nas áreas indígenas nas décadas anteriores à realização do Diagnóstico sócio-demográfico, mas certamente as dificuldades de acesso físico à escola deviam ser enormes, o que justificaria a migração de famílias para aldeias onde ela existia. Tais dificuldades existiam provavelmente tanto no Andirá como no Marau, já que os deslocamentos motivados pela busca de condições melhores de educação referem-se a proporções idênticas de migrantes nessas duas áreas indígenas.

Não são muitos os que migraram à procura de melhores condições de saúde, estando mais presentes no Marau do que no Andirá, de forma geral. Em anos mais próximos à época da pesquisa, porém, as duas áreas se equiparam e apresentam pouquíssimos migrantes que mudaram por esse motivo, o que estaria a indicar a tendência ao desaparecimento dessa causa da migração nas duas áreas. Provavelmente, uma das principais razões do arrefecimento migratório por motivo relacionado à saúde do migrante ou de um familiar seu esteja na expansão dos serviços públicos em toda a Terra Indígena Andirá-Marau, nos últimos anos, por meio, individualmente, da presença do agente indígena de saúde e da razoável mobilidade das equipes de saúde no interior do território indígena.

\footnotetext{
12 Segundo documento da Fundação Nacional de Saúde (Funasa), o agente indígena de saúde é um membro da aldeia que será capacitado para prestar assistência à saúde aos demais integrantes de sua própria aldeia (FUNDAÇÃO NACIONAL DE SAÚDE, 2000).
} 


\section{Migração para as cidades próximas}

Sob um ângulo econômico e social, o processo de migração da terra indígena para a cidade não se difere muito, quanto a seus determinantes, daquele vivido pelos ribeirinhos não-indígenas. Procurando sobreviver num mundo em que se esgotam as fontes naturais de subsistência, especialmente a pesca e a caça, percebendo a falta de solução para seus problemas alimentares e carentes de bons serviços de atendimento à saúde e de educação formal para os fiIhos, tudo isso num ambiente de crescente monetarização e de influência cotidiana da vida e da cultura urbanas, os moradores das terras indígenas veem desenvolver-se a perspectiva de viver na cidade.

Entre os indígenas, é forte a relação com os "parentes" urbanos, e as visitas mútuas acontecem com frequência. Os filhos que vão estudar nas cidades próximas mantêm um vínculo permanente e intenso com suas famílias residentes nas terras indígenas, embora muitos acabem por não regressar após o término dos estudos. Todavia, para todos eles, a terra que deixam continua sendo sua, e o retorno mantém-se sempre como possibilidade.

Dos 678 moradores urbanos sateré-mawé com dez anos e mais de idade entrevistados, 570 não nasceram nas cidades em que estavam vivendo e, entre esses, $78,5 \%$ nasceram em território indígena (Andirá-Marau e Koatá-Laranjal). Parcela significativa dos migrantes residentes nas cidades $(12,6 \%)$ nasceu em áreas rurais próximas às terras indígenas, no interior dos municípios investigados.

\section{Idade, sexo e motivo da migração}

Uma expressiva quantidade de migrantes das cidades investigadas é composta de adolescentes e jovens. Entre os migrantes, $56,2 \%$ têm menos de 25 anos. Todavia, como se pode ver no Gráfico 4, apesar da redução do número de migrantes a partir dos 25 anos, é muito elevada a quantidade daqueles em idades superiores, inclusive de idosos. Dos 231 moradores urbanos com 30 anos ou mais de idade, 220 (95\%) não são naturais das cidades de residência, como já foi visto. A proporção sobe para $97 \%$ quando se trata de moradores com 50 anos e mais.

GRÁFICO 4

Distribuição dos migrantes sateré-mawé na área urbana, por idade e sexo 2002/2003

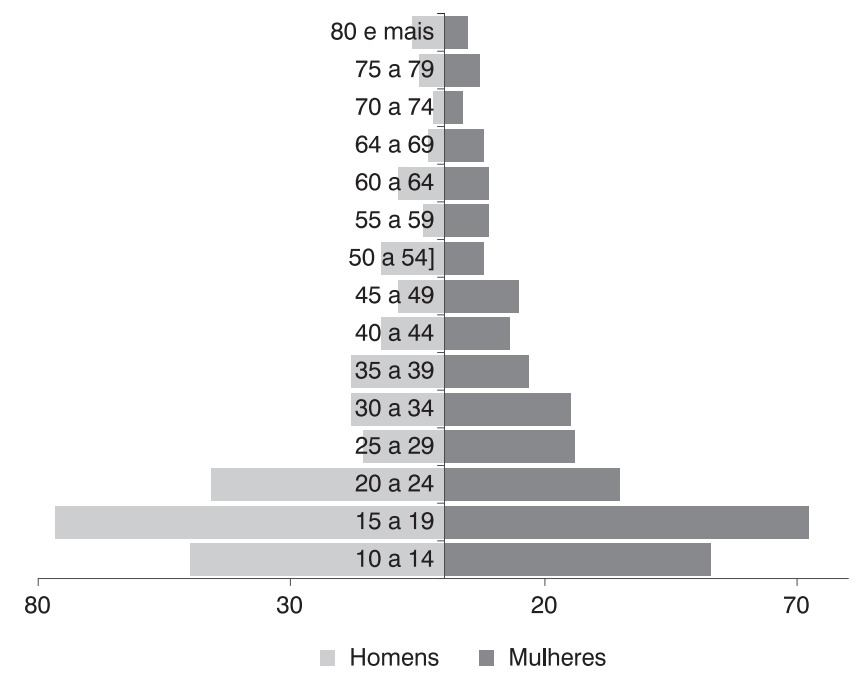

Fonte: Base de dados do Diagnóstico Sócio-Demogrãfico Participativo da População Sateré-Mawé. 
As mulheres sateré-mawé migram mais para as cidades do que os homens, mas sua superioridade numérica não se verifica em todos os grupos etários. Os homens são majoritários nas idades inferiores a 25 anos, a partir do que as mulheres passam a superá-los em número. A forma da pirâmide etária (Gráfico 4) permite afirmar que a relevância do número de adultos e idosos entre os migrantes deve-se ao caráter preponderantemente feminino da migração nessas idades. A emigração de população feminina de áreas rurais para centros urbanos é um padrão bastante conhecido em estudos populacionais, especialmente a distâncias consideradas pequenas, como a observada entre as comunidades indígenas estudadas e as cidades circunvizinhas. No entanto, essa modalidade migratória apresenta algumas especificidades quanto às suas motivações, no caso dos sateré-mawé.

Coerentemente com a reduzida idade da maioria dos imigrantes residentes nas cidades, a principal motivação citada para a migração com destino urbano seria a procura de melhores condições de educação. Este motivo refere-se, certamente, à busca de estabelecimentos educacionais para os adolescentes continuarem os estudos iniciados na terra indígena, que não vão além da quarta série do ensino fundamental. A segunda razão em relevância para a migração relaciona-se às atividades de trabalho (transferência e procura de emprego), tendo sido alegado por $10 \%$ dos moradores entrevistados.

Até os 25 anos de idade, os homens são maioria entre os que migraram à procura de melhores condições de ensino, embora um número expressivo (63) de mulheres jovens também tenha declarado o mesmo motivo para migrar. Não parece existir, a priori, uma explicação satisfatória para esse comportamento diferenciado em relação à migração. É provável que, na concepção da família, o rapaz tenha mais condições do que a jovem de se adaptar a um ambiente desconhecido e adverso, em muitos sentidos. Talvez, justamente por não terem a oportunidade de se mudar para a cidade quando jovens, muitas mulheres o fazem mais tarde - e o fazem mais do que os homens -, mas já não tanto em busca de uma escola para continuar os estudos, e sim, em vários casos, à procura de uma ocupação pela qual possam sobreviver.

Conforme indicam os dados levantados, a migração por motivo de trabalho seria diferenciada segundo o sexo do migrante, com maioria feminina (18 mulheres e sete homens). Não há nenhum homem entre os moradores com menos de 25 anos de idade que emigraram para as cidades à procura de trabalho.

Embora não constitua regra geral, as mulheres indígenas migrantes, até a época da realização da pesquisa, ainda tinham pouco acesso às atividades do trabalho formal, haja vista sua reduzida migração motivada por transferência de trabalho.

\section{Tempo de residência nas cidades}

O principal destino dos sateré-mawé que deixam a área do Andirá para residir na área urbana corresponde às cidades de Parintins e Barreirinha, as mais próximas daquela área indígena. Maués, por sua vez, constitui a referência principal dos sateré-mawé do Rio Marau para a migração com destino urbano.

É recente a migração em direção às cidades próximas das terras indígenas. Em 2002/2003, dois terços dos imigrantes dessas cidades tinham menos de dez anos de residência e, entre estes últimos, outros dois terços haviam fixado residência menos de cinco anos antes daquele período. A julgar pelos dados disponíveis, o grosso da migração dirigia-se, no início, para Barreirinha e Parintins, mas, com o tempo, Maués foi ganhando importância. A participação dos imigrantes dessa cidade no total da migração com destino urbano aumenta de $8,4 \%$, entre os mais antigos (dez anos ou mais de residência), para $29 \%$, entre os mais recentes. Quase $90 \%$ do total de imigrantes de Maués chegaram à cidade nos últimos dez anos, o que a situa como a de migração mais recente entre as quatro cidades estudadas.

Além de mostrar uma perda aparentemente crescente de população da área do Marau, em benefício da cidade de Maués, os dados disponíveis mostram um volume 
migratório ainda maior com destino a $\mathrm{Pa}$ rintins e Barreirinha, com origem na área do Rio Andirá, o que aponta para uma situação de esvaziamento gradativo daquela área. Ressalte-se que essa situação não se deve unicamente à migração para cidades próximas. Mesmo apresentando saldo migratório positivo em relação ao Marau, o Andirá é origem das migrações intensas que determinaram o povoamento das aldeias do Rio Uaicurapá e do Koatá-Laranjal, sem contar os significativos fluxos migratórios com destino a Manaus, capital estadual do Amazonas. Excluindo-se Manaus, as cidades e as áreas indígenas sateré-mawé "receberam" 556 migrantes provenientes da área do Andirá, contra apenas 291 do Marau. Somente da aldeia de Ponta Alegre, no Andirá, saíram 69 dos 160 migrantes de Barreirinha e 168 dos 296 de Parintins. Esses dois valores, somados, perfaziam $60 \%$ dos 397 moradores daquela comunidade em 2002/2003.

\section{Mortalidade infantil}

A rigor, os níveis de mortalidade indígena no Brasil não são bem conhecidos. As principais fontes de dados para calculá-los dependem da disponibilidade e da qualidade das informações específicas do Sistema de Informações sobre a Mortalidade (SIM) e do Sistema de Informações sobre Nascidos Vivos (Sinasc), ambos do Ministério da Saúde (CARDOSO et al., 2005). Também pertencente ao Ministério da Saúde, o Sistema de Informações de Atenção à Saúde Indígena (Siasi) apresenta limitações de diferentes ordens, que vão desde a concepção do formulário de pesquisa até a sua divulgação junto ao público, passando pelas dificuldades de levantamento de campo (SOUSA et al., 2007). Devido a essa situação, como ocorre em relação a populações para as quais não há informações completas ou confiáveis, costuma-se recorrer a técnicas indiretas de estimação dos níveis de mortalidade (BRASS; COALE, 1968).

Embora ofereçam estimativas aceitáveis de indicadores de mortalidade para o conjunto da população (indígenas e não-indígenas), os resultados obtidos com a utilização de técnicas indiretas ${ }^{13}$ têm gerado, para a população indígena, níveis de mortalidade de qualidade duvidosa, com tendência à subestimação, em especial no que se refere à mortalidade infanto-juvenil. ${ }^{14}$

A mortalidade infantil estimada com dados do Diagnóstico sócio-demográfico de 2002/2003 é de 70,3 óbitos por mil nascidos vivos. Diante do caráter específico e localizado desse levantamento, do maior tempo disponível para sua realização e do fato de os entrevistadores terem sido os professores indígenas (TEIXEIRA, 2005), bem como tendo-se em conta problemas existentes com a utilização de dados censitários na estimação da mortalidade infantil, é razoável considerar que os resultados do Diagnóstico sócio-demográfico se aproximam mais do nível de mortalidade infantil dos sateré-mawé do que as informações censitárias.

Entre os fatores que explicariam o nível elevado da mortalidade infantil dos sateré-mawé, poderia estar a precariedade da situação nutricional na área indígena. Segundo relatos de alguns chefes de domicílio nas comunidades, o povo sateré-mawé residente nas áreas indígenas do Andirá-Marau vem sofrendo consideravelmente com a escassez de peixes em sua dieta elementar. Essa carência de sua principal fonte tradicional de proteínas poderia obviamente ser supri-

\footnotetext{
${ }^{13}$ Quando se utiliza método indireto de estimação da mortalidade infantil, o resultado obtido é a probabilidade de que um nascido vivo vá a óbito antes de completar um ano de idade. Esse indicador tem valor próximo ao da taxa de mortalidade infantil, que é dada, num determinado ano, pelo número de óbitos de menores de um ano por cada mil crianças nascidas vivas no ano referido.

${ }^{14} \mathrm{Em}$ recente publicação do IBGE, chama-se a atenção para uma provável subestimação da mortalidade infantil brasileira, feita por técnica indireta, com dados censitários, e cujo valor de 45,9 óbitos por mil nascidos vivos está longe dos 74,6 calculados com base nas informações geradas pelo Siasi, de qualidade também duvidosa (IBGE, 2005). Também para os sateré-mawé, os resultados de mortalidade obtidos a partir de dados censitários parecem subestimados, ficando próximos dos 55 óbitos por mil nascidos vivos em 2000.
} 
da pela compra do peixe em outros locais, o que seu poder aquisitivo não permite. $A$ substituição por outros alimentos, como a carne bovina, suína ou outra, também não encontra respaldo na capacidade de compra dos sateré-mawé.

A redução de peixe na dieta da população sateré-mawé, sem um substituto com mesmo valor proteico, certamente tenderá a prejudicar o estado nutricional das mães, o que influirá na saúde dos filhos desde a concepção, levando provavelmente a uma redução de seu peso ao nascimento, podendo continuar a afetar sua saúde posteriormente, caso sejam alimentados com leite pobre em proteínas nos primeiros meses de vida. Evidentemente, para essa criança, o risco de morrer é sempre maior do que o de outra bem nutrida.

Como um dos fatores que levam à cura da doença, ou à morte provocada por ela, a atividade das instituições encarregadas de zelar pela saúde dos povos indígenas merece enfoque particular, já que de seu funcionamento e organização dependerão a qualidade dos serviços que oferecem e, por extensão, a situação de saúde da população a que elas atendem.

Objetivamente, o atendimento à saúde nas áreas indígenas habitadas pelos sateré-mawé não era de boa qualidade na ocasião em que foi realizado o levantamento de campo do Diagnóstico sócio-demográfico. Partindo da ótica do usuário, a pesquisa procurou verificar vários aspectos desse atendimento, tendo seu relatório apontado a existência de deficiências generalizadas no serviço realizado, em especial nos que se referiam à saúde reprodutiva, cujo atendimento pela instituição encarregada do Distrito Sanitário deixava a desejar (TEIXEIRA, 2005).

Seja pela ausência de profissionais capacitados, seja pela estruturação deficiente do trabalho na área indígena, a organização dos serviços, de modo geral, é fortemente apoiada no trabalho do agente indígena de saúde (AIS), o qual tem pouca capacidade resolutiva dos agravos.

A situação mostra-se especialmente inquietante quando se examina a cobertura dos serviços de saúde para a mulher indíge- na grávida. Entre as mulheres sateré-mawé que haviam engravidado no ano anterior à pesquisa, menos de $40 \%$ declararam ter procurado o serviço de saúde. No entanto, o que chama a atenção é a precariedade de atendimento à mulher grávida no que se refere aos procedimentos que devem ser adotados no acompanhamento da gravidez.

De fato, apenas nove mulheres, entre as 141 que foram atendidas pelo serviço, fizeram a quantidade de consultas recomendada (quatro ou mais). A realização de exames de pré-natal pelas mulheres que procuraram o serviço é também muito abaixo do esperado. O exame realizado em maior quantidade (urina) foi feito por $75 \%$ das mulheres atendidas, quando o recomendável é $100 \%$. Para o restante dos exames de pré-natal (sangue, pressão arterial, peso), a cobertura é ainda menor.

As mulheres grávidas atendidas pelo serviço de saúde foram vacinadas em sua quase totalidade. No entanto, das 130 grávidas vacinadas, apenas 23 receberam o número de doses preconizadas pelas orientações correntes de atenção à gravidez. Se for considerado o número total de mulheres que ficaram grávidas no ano, a cobertura vacinal cai para 5,8\%. Cumpre ressaltar que a cobertura na área urbana, muito embora ainda insuficiente, é de $40 \%$.

Assim, não chega a surpreender a persistência de elevados níveis de mortalidade infantil entre os sateré-mawé. De um lado, a má cobertura e a ineficiência na assistência pré-natal e ao recém-nascido irão influir nas taxas de mortalidade perinatal e, de outro, a elaboração de diagnósticos e a prescrição de medicamentos por pessoas mal treinadas podem conduzir a erros na detecção e cura de doenças como as infecciosas, as parasitárias e as pulmonares, que correspondem a $80 \%$ de todos os óbitos de menores de um ano do Estado do Amazonas (DATASUS, 2003/2005) e, certamente, também dos sateré-mawé.

Como um dos determinantes socioeconômicos na mortalidade infantil, o saneamento básico deficiente contribui para os níveis elevados das doenças infecciosas e parasitárias, especialmente das diarreicas. Nas terras dos sateré-mawé, as condições 
do abastecimento de água e do destino dos dejetos humanos não contribuem para assegurar um padrão desejável de saúde para a população. Ao contrário, a água utilizada para o consumo das famílias tem como fontes, em quase $90 \%$ dos casos, os rios e igarapés que banham as comunidades, os quais são também utilizados para os banhos diários, a lavagem de roupa, o lazer da população, o transporte fluvial em barcos que são verdadeiras fontes de poluição e de dejetos diversos. Os poços artesianos e as cacimbas comunitárias eram utilizados, em 2002/2003, por $20 \%$ dos domicílios da área do Marau e em apenas seis domicílios no Andirá.

Quanto ao destino dos dejetos humanos, as comunidades de todas as quatro áreas estudadas são servidas, de forma satisfatória, pelas privadas externas. É necessário frisar, no entanto, que, entre os 76 domicílios que não são servidos por esse tipo de escoamento, 60 encontram-se no Marau. Desses últimos, 55\% estão concentrados nas comunidades situadas próximas às nascentes do Rio Marau, cuja população não passa dos $25 \%$ do total dos habitantes dessa área indígena.

Outra característica dessas nascentes está na falta de escolarização de grande parte das crianças que aí residem. Em 2002/2003, era reduzida a proporção de crianças fora da escola na Terra Indígena Andirá-Marau. Todavia, nas cinco comu- nidades mais próximas às nascentes da área do Marau, apenas $64 \%$ das crianças em idade escolar estavam matriculadas, ao passo que nas demais comunidades da mesma área a proporção correspondente ultrapassava os $90 \%$.

Salvo alguma deficiência nos dados apresentados, a combinação de algumas das características socioeconômicas e espaciais (segurança alimentar, saneamento básico, educação e outras) das comunidades próximas às nascentes do Rio Marau as situam como as mais carentes e desassistidas da Terra Indígena Andirá-Marau. Como consequência direta ou indireta, essas comunidades, que têm pequeno peso na população total do Marau, detêm cerca de $40 \%$ de todos os óbitos de filhos de mulheres com menos de 25 anos de idade nessa área indígena. $\mathrm{Na}$ Tabela 6 , que mostra as estimativas dos níveis de mortalidade infantil nas terras indígenas, observam-se os diferenciais francamente desfavoráveis aos moradores da área próxima às nascentes, no Marau. Note-se também que, nas nascentes do Andirá, a mortalidade infantil é superior à do restante da área do mesmo nome, porém, as diferenças são significativamente menores do que no Marau.

Os resultados aqui expostos parecem indicar que a situação das áreas de nascente situadas na bacia do Rio Marau explicaria uma parcela significativa do diferencial de

TABELA 6

Probabilidade de crianças sateré-mawé morrer antes de completar um ano de vida, segundo o local de residência das mães

2002/2003

\begin{tabular}{lc}
\hline Local de residência das mães & Probabilidade de morte infantil (por mil nascidos vivos) \\
\hline Área urbana (1) & $\mathbf{8 1 , 4}$ \\
Área indígena & $\mathbf{7 1 , 6}$ \\
Marau & 78,1 \\
$\quad$ Nascentes & 95,6 \\
$\quad$ Restante da Área & 69,8 \\
Andirá & 63,5 \\
$\quad$ Nascentes & 70,1 \\
Restante da Área & 61,1 \\
Uaicurapá e Koatá-Laranjal & 72,6 \\
Total & $\mathbf{7 0 , 3}$ \\
\hline
\end{tabular}

Fonte: Base de dados do Diagnóstico Sócio-Demográfico da População Sateré-Mawé.

(1) Por ter sido estimado a partir de um número reduzido de óbitos, o resultado para a área urbana tem pouca precisão. 
mortalidade existente entre aquela área indígena e o Andirá, muito embora a população, nessas nascentes, seja pouco representativa no Marau. Uma análise da mortalidade infantil, mais detalhada, poderia ser realizada a partir de informações levantadas em pesquisa de campo específica, que buscasse concentrar-se nos possíveis determinantes da elevada mortalidade do Andirá-Marau e dos diferenciais em seu interior.

\section{Considerações finais}

Os sateré-mawé são um povo indígena que, em 2002/2003, era constituído de mais de nove mil homens e mulheres, habitando principalmente uma região que engloba parte do Estado do Amazonas e parte do Pará, a Terra Indígena Andirá-Marau. Estão também distribuídos pelas áreas rurais circunvizinhas e por várias cidades da região, além da capital do Estado do Amazonas, Manaus, e em uma comunidade situada em território Munduruku, a Terra Indígena Koatá-Laranjal.

Um levantamento censitário e participativo nas duas terras indígenas mencionadas e em quatro cidades das proximidades, realizado em 2002/2003, contabilizou 7.502 sateré-mawé nas duas terras indígenas e 998 naquelas áreas urbanas, possibilitando obter informações demográficas e socioeconômicas sobre esse povo indígena.

O povo sateré-mawé apresenta uma distribuição etária jovem. Nas áreas indígenas, a distribuição etária segue os padrões populacionais em que a fecundidade e a mortalidade na infância são elevadas. Ali, o número de mulheres é inferior ao dos homens nos primeiros grupos etários adultos, presumivelmente devido a uma maior emigração feminina com destino urbano. Há uma concentração incomum de população em torno das idades entre 55 e 60 anos, que pode estar relacionada a problemas na declaração de idade dos entrevistados, por conta de fatores como a aposentadoria por idade (55 anos para as mulheres e 60 para os homens). Nas cidades, a população é, em sua maioria, jovem, devido a uma fecundidade relativamente elevada e a uma população imigrante também jovem, em busca de trabalho e de continuação dos estudos iniciados nas áreas indígenas.

Os sateré-mawé estão entre os povos indígenas com os maiores níveis de fecundidade do Brasil, seja em área indígena, seja nas cidades. A taxa de fecundidade das terras indígenas encontra equivalentes nas de outros povos do Estado do Amazonas e mesmo, em alguns casos, em outros locais do Brasil. O nível urbano está em patamares relativamente elevados devido, também, em grande parte, ao caráter recente da migração para as cidades. O padrão de fecundidade das mulheres sateré-mawé é jovem, mas a gravidez na adolescência é um fenômeno menos frequente do que no restante do Brasil.

Existe uma elevada mobilidade populacional tanto no interior das terras indígenas como dessas para as cidades próximas. Os motivos para migrar, entre os sateré-mawé, variam conforme o tempo em que a migração ocorreu. Um tipo de migração que existe desde os tempos antigos é o das pessoas que se casam, sendo necessário que um deles vá morar na aldeia do outro. Este tipo de migração era e é feito majoritariamente por mulheres. A migração por motivo de trabalho tem se desenvolvido e é realizada, principalmente, pelos professores indígenas. Outra causa da migração é dada pelos conflitos nas comunidades, em que famílias saem de suas aldeias e vão criar novas comunidades em outras áreas sateré-mawé.

$\mathrm{Na}$ área urbana, é migrante a quase totalidade dos sateré-mawé com mais de 30 anos de idade. Os homens são maioria no que se refere à mudança por motivo de estudos e até os 25 anos de idade. Daí em diante, as mulheres passam a ser majoritárias e têm como um dos principais motivos de migração a procura de trabalho.

Constata-se que a área indígena estudada apresenta mortalidade infantil elevada. Alguns elementos de explicação para essa situação estariam relacionados com características socioeconômicas, de infraestrutura e nutricionais do povo sateré-mawé. Um deles refere-se ao desaparecimento do peixe, alimento básico, em importantes áreas, comprometendo uma relevante fonte de proteínas para as mães e seus filhos recém- 
-nascidos. O outro está relacionado com o atendimento à saúde na área indígena, com um quadro indicando má cobertura e deficiências e carências operacionais.

Num outro nível de abordagem, percebeu-se que a mortalidade infantil apresenta diferenciais espaciais significativos no território indígena, tanto entre a área do Andirá e a do Marau como entre as comunidades desta última área. Nas comunidades próximas às nascentes dos rios que banham a

\section{Referências}

AZEVEDO, M. M. Demografia dos povos indígenas do Alto Rio Negro. Revista Brasileira de Estudos de População, Belo Horizonte, v. 11, n. 2, p. 235-244, 1994. Disponível em: $<$ http://www.abep.org.br>.

. Povos indígenas do Alto Rio Negro: Padrões de nupcialidade e concepções sobre reprodução. In: ENCONTRO NACIONAL DE ESTUDOS POPULACIONAIS, XIV. Anais... Caxambu: Abep, 2004. Disponível em: <http://www.abep.org.br>.

Urbanização e migração na cidade de São Gabriel da Cachoeira, Brasil. In: ENCONTRO NACIONAL DE ESTUDOS POPULACIONAIS, XV. Anais... Caxambu: Abep, 2006. Disponível em: <http://www. abep.org.br>.

BATISTA, M. P. O movimento indígena Sateré-Mawé do Rio Andirá. Mimeografado.

BRASS, W.; COALE, A. J. The demography of Tropical Africa. Office of Population Research. Princeton: Princeton University Press, 1968.

CARDOSO, A. M.; SANTOS, R. V.; COIMBRA Jr., C. E. A. Mortalidade infantil segundo raça/cor no Brasil: o que dizem os sistemas. Cad. Saúde Pública, v. 21, n. 5, p.1.6021.608, set./out. 2005.

DATASUS. Indicadores de saúde/Estatísticas Vitais - mortalidade e nascidos vivos/óbitos infantis, 2003/2005. Disponível em: <http:// tabnet.datasus.gov.br/cgi/tabcgi.exe?sim/ cnv/infam.def>. Acesso em: 09 set. 2007. área do Marau, ela é extremamente elevada, chegando a 95,6 óbitos por mil nascidos vivos (contra uma média de 71,6 das duas áreas). A constatação de mal atendimento em termos de infraestrutura (educação e saneamento) nessas aldeias sugere que as más condições de vida, aí refletidas, devem constituir importante fator de determinação dos altos índices de mortalidade infantil nessa subárea, com reflexos nos níveis de todo o Andirá-Marau.

FUNDAÇÃO NACIONAL DE SAÚDE. Diretrizes para projetos físicos de estabelecimentos de saúde em áreas indígenas. Brasília: Funasa, 2000.

IBGE. Tendências demográficas: uma análise dos indígenas com base nos resultados da amostra dos censos demográficos de 1991 e 2000. Rio de Janeiro, 2005.

KRETER, A. C.; BACHA, J. C. J. Avaliação da eqüidade da Previdência no meio rural do Brasil. Rev. Econ. Sociol. Rural, v. 44, n. 3, jul./set. 2006. Disponível em: <http:// www.scielo.br/scielo.php?pid=s0103$-20032006000300006 \&$ script $=$ sci_arttext $>$.

LORENZ, S. da S. Sateré-Mawé: os filhos do guaraná. São Paulo: Centro de Trabalho Indigenista, 1992.

PAGLIARO, H. A revolução demográfica dos povos indígenas: a experiência dos Kaiabi do Parque Indígena do Xingu, Mato Grosso (1970-1999). Tese (Doutorado). São Paulo: Faculdade de Saúde Pública, Universidade de São Paulo, 2002.

PAGLIARO, H.; MENDAÑA, L. G. S.; RODRIGUES, D.; BARUZZI, R. G. Comportamento demográfico dos índios Waurá no final do século XX. In: GENERAL POPULATION CONFERENCE, XXIV. Anais... Salvador: IUSSP, 2001, p. 1583-1594.

PAGLIARO, H.; AZEVEDO, M. M.; SANTOS, R. V. Demografia dos povos indígenas no Brasil: um panorama crítico. In: PAGLIARO, H.; AZEVEDO, M. M.; SANTOS, R. V. 
(Orgs.). Demografia dos povos indígenas no Brasil. Rio de Janeiro: Fiocruz/Abep, 2005, p. 11-32.

SOUSA, M. C.; SCATENA, E. J. H. C.; SANTOS, R. V. O Sistema de Informações da Atenção à Saúde Indígena (SIASI): criação, estrutura e funcionamento. Cad. Saúde Pública, v. 23, n. 4, p. 853-861, abr. 2007.
SOUZA, L. G. de; SANTOS, R. V. Perfil demográfico da população indígena Xavánte de Sangradouro - Volta Grande, Mato Grosso (1993-1997), Brasil. Cad. Saúde Pública, v. 17, n. 2, p. 355-366, 2001.

TEIXEIRA, P. Sateré-Mawé: retrato de um povo indígena. Manaus: Unicef/Unfpa, 2005.

\section{Resumen}

Demografía de un pueblo indígena del Amazonas brasileño: los sateré-mawé

Un estudio sociodemográfico de censo participativo sobre la población sateré-mawé, realizado en 2002 y 2003, en dos tierras indígenas y en cuatro ciudades situadas en el oeste del estado de Amazonas, reveló información de relevancia para la comprensión de las características demográficas, económicas, sociales y culturales de aquel pueblo indígena. En el cómputo general, fueron contados y entrevistados 7.502 indígenas en las tierras indígenas y 998 en las áreas urbanas. El presente trabajo procura analizar, en los datos recogidos, las proporciones referentes a las características sociodemográficas de los sateré-mawé, incluyéndose la estructura de edad y por sexo, la fecundidad, la mortalidad y la migración. El pueblo saterémawé presenta una pirámide de edad joven, fruto de una fecundidad elevada y de una población anciana reducida. Se perciben intensos flujos migratorios, tanto en el interior de las tierras indígenas donde habitan los sateré-mawé, como en dirección a las ciudades próximas, en los que estos flujos son de carácter relativamente reciente. A su vez, la mortalidad infantil en el territorio indígena es elevada y espacialmente diferenciada, siendo mayor en las cabeceras de uno de los dos principales ríos que cortan el territorio sateré-mawé. Algunos elementos de determinación de los niveles y de los diferenciales de la mortalidad de los niños se encuentran en las características socioeconómicas, de infraestructura y nutricionales del pueblo sateré-mawé.

Palabras-clave: Pueblos indígenas. Distribución de edad. Fecundidad. Migración. Mortalidad infantil.

\section{Abstract \\ Demography of an indigenous people in the Brazilian Amazon: the satére-mawé}

A participative sociodemographic census survey on the sateré-mawé population, carried out in 2002 and 2003, in two indigenous territories and four cities west of the state of Amazonas revealed demographic, economic, social and cultural information about the indigenous people. In all, 7,502 people were interviewed in their lands and 998 in urban areas. The present study aimed to analyze the sociodemographic characteristics of the sateré-mawé, including age and sex distribution, fertility, mortality, and migration. Most of the sateré-mawé are young, because of their high fertility and reduced aged population. There are intense, relatively recent, migratory flows, both towards the land occupied by the sateré-mawé and to nearby cities. Child mortality in the territory is high and uneven, higher in the head of one of the main rivers going through the sateré-mawé territory. The socioeconomic, infrastructural and nutritional characteristics of 
the sateré-mawé people also determine some elements of the levels and differentials in child mortality.

Keywords: Indigenous people. Age distribution. Fertility. Migration. Child Mortality.

Recebido para publicação em 06/11/2010

Aceito para publicação em 08/08/2011 